\title{
Changes in Behavior and Ultrasonic Vocalizations During Pair Bonding and in Response to an Infidelity Challenge in Monogamous California Mice
}

\author{
Joshua D. Pultorak ${ }^{1 *}$, Sarah J. Alger ${ }^{2}$, Steven O. Loria ${ }^{1}$, Aaron M. Johnson ${ }^{3}$ and \\ Catherine A. Marler ${ }^{1,4}$
}

${ }^{1}$ Department of Integrative Biology, University of Wisconsin-Madison, Madison, WI, United States, ${ }^{2}$ Department of Biology, University of Wisconsin-Stevens Point, Stevens Point, WI, United States, ${ }^{3}$ School of Medicine, New York University, New York, NY, United States, ${ }^{4}$ Department of Psychology, University of Wisconsin-Madison, Madison, WI, United States

OPEN ACCESS

Edited by:

Nancy G. Solomon,

Miami University, United States

Reviewed by:

Kerstin Musolt,

Brooklyn College (CUNY), United States

Ryan Ying Wong,

University of Nebraska Omaha,

United States

Laura M. Hurley,

Indiana University Bloomington,

United States

*Correspondence: Joshua D. Pultorak

pultorak@wisc.edu

Specialty section:

This article was submitted to Behavioral and Evolutionary Ecology,

a section of the journal

Frontiers in Ecology and Evolution

Received: 31 March 2018 Accepted: 02 August 2018

Published: 28 August 2018

Citation:

Pultorak JD, Alger SJ, Loria SO, Johnson AM and Marler CA (2018)

Changes in Behavior and Ultrasonic Vocalizations During Pair Bonding and in Response to an Infidelity Challenge

in Monogamous California Mice.

Front. Ecol. Evol. 6:125.

doi: 10.3389/fevo.2018.00125
Despite recent exciting research about pair bonding, little is known about how mammalian vocalizations change with the initiation and maintenance of pair bonding in monogamous species. Moreover, even less is known about the significance of pair bond resilience in the face of social challenges. In the strictly monogamous California mouse (Peromyscus californicus), we measured changes in ultrasonic vocalizations (USV) and other behaviors within male-female dyads over the course of pair bonding and characterized associations of USVs with affiliation and aggression. After 1 week of cohabitation, pairs exhibited decreased aggression and "bark" USVs, and increased "simple sweep" and "sustained vocalization" (SV) USV types. Accordingly, the number of barks was associated with aggression, whereas the number of simple sweeps and the number, call duration and bout size of SVs corresponded with affiliation. We then experimentally assessed the impact of an infidelity challenge ( 1 week cohabitation with an unfamiliar, opposite-sex, extra-pair individual) for both sexes on pair social behavior, acoustic behavior, and reproductive success. The infidelity challenge temporarily disrupted pair bond interactions during pair reunion, independent of which sex experienced the infidelity challenge, via both increases in aggression and barks, and a stunting of affiliation and SVs, compared to control pairs. Pair reproductive success, in the form of birth latency, litter size, pup survival and birth weight, did not differ between infidelity challenge pairs and controls. The quality of pair interactions, however, was associated with reproductive success: aggression during pair reunion across all pairs was associated with a lower likelihood of successfully producing a litter. Similarly, among infidelity challenge pairs, but not the controls, there was a positive association between pair affiliation and paternal care, and a negative association between pair aggression and paternal care. Overall, the infidelity challenge revealed a weak negative effect on reproductive success, but we speculate, based on our results, that greater resiliency of a pair bond can moderate negative effects of a social challenge.

Keywords: infidelity, pairbond, USVs, monogamy, California mouse, extra-pair, communication 


\section{INTRODUCTION}

Among socially monogamous species in a variety of taxa, intersexual acoustic communication plays a key role in pair bond formation and maintenance (Geissmann and Orgeldinger, 2000; Smith et al., 2008; Hall, 2009). Investigation of one form of acoustic communication, ultrasonic vocalizations (USVs), has provided an emerging, valuable lens through which to examine social dynamics in rodents and other small mammals (Brudzynski, 2018). Rodent models of monogamy have been pivotal in our understanding of the regulation of mammalian pair bonding and mate fidelity (Wang and Aragona, 2004; Kingsbury et al., 2012; Lieberwirth and Wang, 2016), but USVs as they relate to pair bonding in monogamous rodents have not been examined until recently. Additionally, the elusive measure of pair bond quality has not been measured in the face of an infidelity challenge.

Mate fidelity is a characteristic of monogamy in the small subset of mammals that express monogamy (Emlen and Oring, 1977; Kleiman, 1977; Dewsbury, 1988). Among monogamous human couples, infidelity may weaken pair bonds (Fletcher et al., 2015) and is widely regarded as one of the most prominent factors influencing emotional distress and divorce (Atkins et al., 2001; Sweeney and Horwitz, 2001; Previti and Amato, 2004). Yet, very little is known about the impact of infidelity on monogamous social bonding in non-human animals and what mechanisms may characterize resiliency in response to this challenge to the integrity of the pair bond. Mated males and females of many monogamous species form strong social pair bonds that are often typified by prolonged association, close proximity, vocal signatures such as duetting, the exclusion of extraneous adults, and sexual fidelity (Kleiman, 1977; Mock and Fujioka, 1990; Geissmann and Orgeldinger, 2000; DietrichBischoff et al., 2006; Martin et al., 2007). Several studies have highlighted negative relationships between extra pair copulations and fitness consequences in socially monogamous birds (for reviews see Choudhury, 1995; Griffith et al., 2002; Spoon et al., 2007; Culina et al., 2015; Schroeder et al., 2016 for a recent meta-analysis), but notably, these are correlational investigations. Other studies have examined the effects of pair separation on stress responses, as measured by the occurrence of distress behavior and/or increases in glucocorticoids in birds (RemageHealey et al., 2003), primates (Fernandez-Duque et al., 1997; Shepherd and French, 1999; Ginther et al., 2001), and rodents (Starkey and Hendrie, 1998; Martin et al., 2006; Bosch et al., 2009; Sun et al., 2014). Overall, however, little is known about the impact of infidelity, or perceived infidelity, during this separation period on the dynamics of the pair bond upon reunion and on reproductive success measures. We used a longitudinal design to experimentally test the impact of an extra-pair cohousing treatment on pair behavior and acoustic communication in California mice (Peromyscus californicus). The treatment provided the opportunity of one individual of a pair to mate and/or form a bond with an extra-pair individual during a 1-week separation period and acted as an infidelity challenge to the pair.

The California mouse is an ideal system for studies of vocalizations and pair bonding because it is a strictly monogamous species (Ribble, 1991) that forms permanent and stable pairs under field conditions (Dudley, 1974; Ribble and Salvioni, 1990; Gubernick and Teferi, 2000). However, when provided an opportunity in the laboratory, $\sim 15 \%$ of males and females copulated outside the pair bond (Gubernick and Nordby, 1993), suggesting at least some capacity for extra-pair mating. Both parents care for the young (e.g., Gubernick and Alberts, 1987; Marler et al., 2003; Rosenfeld et al., 2013) and fathers contribute significantly to offspring survival (Gubernick and Teferi, 2000). Additionally, both male and female California mice produce USVs (Briggs and Kalcounis-Rueppell, 2011) and they produce similar USVs in the wild and the laboratory (Kalcounis-Rueppell et al., 2010). USVs occur at high levels in the laboratory between unfamiliar, opposite-sex individuals (Pultorak et al., 2015), between unfamiliar same-sex individuals (Rieger and Marler, 2018), and between bonded pair mates (Pultorak et al., 2017). Amounts of specific USV types produced between pairs separated by a wire mesh are predictive of later affiliative behavior (Pultorak et al., 2017). Furthermore, bonded females respond differently to playbacks of their male partner's USV s compared to an unfamiliar male's USV s when compared to background noise (Pultorak et al., 2017). Internal neurobiological changes are indirectly evident in males that have become bonded because testosterone injections inhibit USV production in pair bonded males but not sexually naïve males (Pultorak et al., 2015). Understanding the functions of USVs in this monogamous system may enhance our understanding of the functions of vocal signals in other systems in which long-term relationships are formed between individuals.

To understand our predictions, it is necessary to provide background for the general categorizations of USVs in California mice. We used four categories of adult vocalizations in California mice, adapted from previous laboratory (Pultorak et al., 2015, 2017) and field (Kalcounis-Rueppell et al., 2006, 2010; Briggs and Kalcounis-Rueppell, 2011) studies. These vocal categories include "simple sweeps," "complex sweeps," "sustained vocalizations (SVs)," and "barks," (spectral information provided in the Methods). Given previous work indicating that complex sweep and SV calls between partners separated by mesh wire predict later pair affiliation (Pultorak et al., 2017), and that SV calls are produced at high rates in the field among bonded pairs (Briggs and Kalcounis-Rueppell, 2011), we predicted that complex sweeps and SVs would increase as pairs form bonds. In contrast, bark calls [first described in Peromyscus in a field study (Kalcounis-Rueppell et al., 2006)] and aggression are positively associated, at least within same-sex interactions (Rieger and Marler, 2018). Thus, we predicted a decrease in barks as the pair bonds form. Finally, we predicted that an infidelity challenge would disrupt pair bonds, as indicated by a reduction in affiliation, complex sweeps and SVs and an increase in aggression and barks toward their original partner, as compared to pairs not exposed to an infidelity challenge.

We addressed three core questions in this study: (1) How does ultrasonic communication and behavior within pairs change during the formation of the pair bond? (2) What are the behavioral correlates of specific USV types emitted by pairs? (3) What are the consequences of an "infidelity" challenge, 
via rehousing with an extra-pair, opposite sex conspecific, on subsequent pair ultrasonic communication, pair behavior, and measures of reproductive success? To address these questions, we assessed pair behavior and USVs during brief dyadic social interactions before and after an infidelity challenge or pair separation in a 28-day longitudinal design. We performed the infidelity challenge separately for both sexes, maintained a pair separation group and an undisturbed, no-separation pair group as controls. Following the dyadic behavioral testing regimen, we measured litter production (birth latency, litter size, mean pup weight, and pup survival) and paternal behavior during pup retrieval tests (latency to approach pup, huddling, licking and grooming) to assess pair reproductive success.

\section{METHODS}

\section{Animal Use and Housing}

We used 55 male and 55 female California mice (age $>4$ mo) reared in a colony in our laboratory at the University of Wisconsin-Madison. Animals were given water and food (Purina $5015^{\mathrm{TM}}$ mouse chow) ad libitum and housed in standard cages $(48.3 \mathrm{~cm} \times 26.7 \mathrm{~cm} \times 15.6 \mathrm{~cm})$ with $1-3$ other same-sex conspecifics (minimum of 4 mo co-housing) prior to pairing. Colony and testing rooms were maintained at $20-23^{\circ} \mathrm{C}$ under a 14:10 light/dark cycle with lights on at 2,200 h. Animals used in pairs or extra-pair dyads shared no common ancestry for a minimum of two prior generations, were sexually naïve, and did not choose their partners (i.e., pairs were "forced"). All behavioral tests were conducted under red light within $3 \mathrm{~h}$ after the onset of the dark cycle, corresponding to the highest activity rates for P. californicus (Marler, unpublished data). All applicable international, national, and/or institutional guidelines for the care and use of animals were followed and were in adherence with the University of Wisconsin-Madison Research Animal Resource Committee (RARC) and Institutional Animal Care and Use Committee (IACUC; L0021-0-03-10).

\section{Social Challenge Conditions and Timeline of Trials}

Dyadic (male + female) behavioral social interaction trials were conducted once every 7 days over a period of 28 days (see Figure 1 for a timeline diagram). Since previous data from our laboratory suggest that a majority of pairs copulate within approximately the first week of co-housing and are found to begin nesting together in this period (Gleason and Marler, 2010; Pultorak et al., 2017), we considered day 7 to represent the "pair development" phase. Behavioral trials for all pairs occurred at pair introduction (day 0) and pair development (day 7). On day 14 prior to the trial, pairs were randomly assigned to one of four social challenge conditions: (1) male infidelity challenge condition ( $n=11$ pairs), in which the male was separated from his mate and housed with an extra-pair unfamiliar female for 7 days (and the original female pairmate was singly-housed), (2) female infidelity challenge condition ( $n=11$ pairs), in which the female was separated from her mate and housed with an extra-pair unfamiliar male for 7 days (and the original male pairmate was singly-housed), (3) separation control condition
( $n=11$ pairs), in which both pair members were separated and singly-housed for 7 days, and (4) no-separation control condition ( $n=11$ pairs), in which the pair remained housed together, undisrupted. For social challenge conditions involving pair separation, members of a pair were housed in separate rooms, outside of their auditory and olfactory range.

We defined the "control supergroup" as all pairs in the separation control condition and no-separation condition ( $n=22$ pairs) and similarly, we defined the "infidelity supergroup" as all pairs in the male infidelity challenge condition and female infidelity condition ( $n=22$ pairs). Trials on day 14 for the control supergroup involved the established pair members, whereas trials on day 14 for the infidelity supergroup involved one pair member and the extra-pair (unpaired, sexually naïve, unfamiliar, and opposite-sex) individual. Immediately after the trial on day 14, the newly formed dyads among the infidelity supergroup were placed in a clean cage and housed together for 7 days. At pair reunion on day 21, trials were interactions of the original members of a pair (i.e., reunion of the pair for all social challenge conditions involving pair separation). These original pairs were then housed together again for the duration of the experiment. On day 28, a final trial ("pair re-establishment") was conducted for all original pairs.

\section{Dyadic Social Interaction Test Procedure}

Each trial consisted of a 5-min behavioral interaction of malefemale dyads in a large, neutral Plexiglas arena $(90 \mathrm{~cm}$ long $\times$ $46 \mathrm{~cm}$ wide $\times 43 \mathrm{~cm}$ high) with aspen bedding. The male was placed in the arena $10 \mathrm{~min}$ prior to each trial, similar to previous work examining dyadic social interactions in California mice (Gleason and Marler, 2010; Pultorak et al., 2015), mimicking the female-biased dispersal pattern in this species (Ribble, 1991). Video recording (Panasonic SDR-SW20, Panasonic Corporation, Kadoma, Osaka, Japan) and audio recording (see below) were initiated simultaneously with the addition of the female.

Behaviors were scored by experienced observers blind to social challenge condition, and inter-rater reliability was assessed for $5 \%$ of the trials (intraclass correlation coefficient $>0.90$ for all measures). Since our primary questions concerned levels of affiliative and aggressive behaviors of the pair, we counted the total number of affiliative behaviors and aggressive behaviors of the dyad (male + female) for each trial. Affiliative behaviors included approaches, follows (continual pursuit of the other ambulatory animal at a slow consistent pace) and sniffs (investigation of the other stationary animal in nose-to-nose or nose-to-anogenital contact). These behaviors were categorized as affiliative and not just investigatory because they each negatively correlated with aggressive behaviors in analyses of all trials in the experiment (Spearman's rank correlation, $N=213, P$-values $\leq 0.001$ ). Aggressive behaviors included chases (movement at a rapid pace toward the other animal, often resulting in biting or wrestling) and wrestles (aggression develops into a tumble in which biting can occur). Behavioral measures used were defined in previous studies (Gleason and Marler, 2010; Pultorak et al., 2017). We provide more details of the raw behavior data, as well as USV data, for each phase of the experiment as Supplemental Materials. 


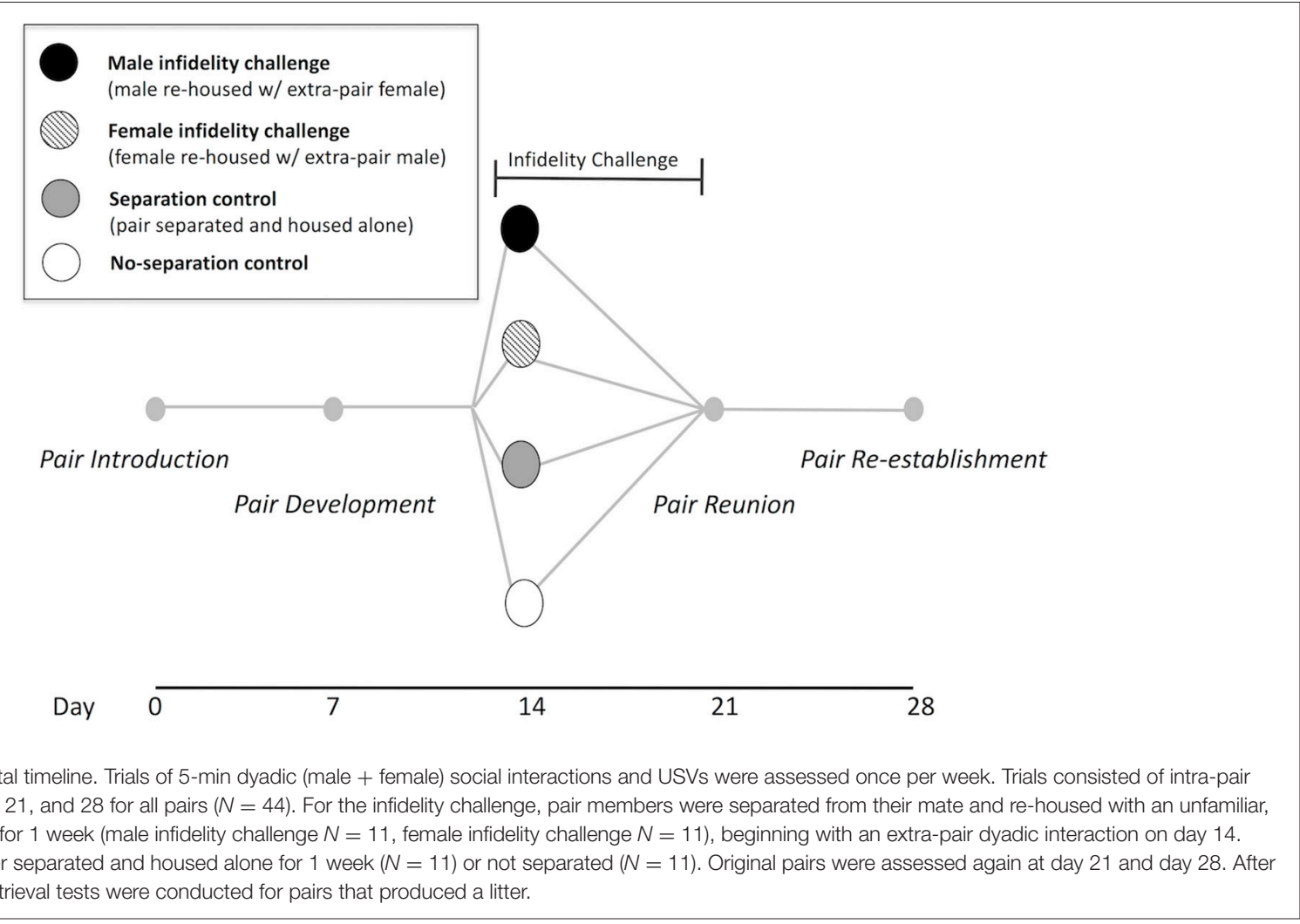

\section{USV Recording and Analysis}

USVs were recorded with a centrally located Emkay/Knowles FG series microphone capable of detecting broadband sound (10$120 \mathrm{kHz}$ ) via an Ultra Sound Gate USG416 interface (Avisoft Bioacoustics, Berlin, Germany). The microphone was placed in the middle of the arena along the back wall $(45 \mathrm{~cm}$ from each side wall) at a height of $30 \mathrm{~cm}$. Recordings were collected at a $250 \mathrm{kHz}$ sampling rate with 16 bit resolution using RECORDER software (Avisoft Bioacoustics, Berlin, Germany). Spectrograms were produced with a 512 FFT (Fast Fourier Transform), high pass filter at $10 \mathrm{kHz}$, and $50 \%$ frame overlap using Avisoft-SASLab Pro sound analysis software (Avisoft Bioacoustics).

Since the vocalizer could not be determined, all USV measures reported are from the dyad (male + female). Counts of calls were done by experienced observers blind to condition and inter-rater reliability was assessed for $5 \%$ of the trials (intraclass correlation coefficient $>0.90$ for each USV type). Call durations of SV type USVs were extracted and exported for analysis. SV mean call duration (i.e., previously termed "mean syllable duration," Pultorak et al., 2017 and altered based on Kalcounis-Rueppell et al., 2018) was calculated for each trial. We used a clustering program ("group.pl") to automatically cluster SV calls into bouts (i.e., phrases) of 1-14 calls (i.e., syllables) per bout based on a maximum inter-syllable interval of $300 \mathrm{~ms}$ (i.e., twice the $150 \mathrm{~ms}$ peak of a distribution of inter-syllable intervals; for more detail see Pultorak et al., 2017). Mean bout size (i.e., "mean phrase size," Pultorak et al., 2017), equivalent to the total number of SV calls in the trial divided by the total number of bouts in trial, was calculated for each trial.

\section{Categories of Ultrasonic Vocalizations}

(1) Simple sweeps are one-syllable, typically downward frequency-modulated, short calls $(<50 \mathrm{~ms})$ with a peak frequency around $40 \mathrm{kHz}$. (2) Complex sweeps are also frequency-modulated but exhibit a much higher peak frequency $(\sim 100 \mathrm{kHz})$, a longer duration $(<100 \mathrm{~ms})$, and typically contain multiple inflection points. (3) SVs are relatively flat (i.e., little frequency modulation), exhibit a relatively long duration $(\sim 100-1,000 \mathrm{~ms})$ and a peak frequency around $20 \mathrm{kHz}$, and often occur in bouts (i.e., previously described as "phrases") that vary in the number of calls (i.e., previously described as "syllables"; Kalcounis-Rueppell et al., 2018) in a given bout (Briggs and Kalcounis-Rueppell, 2011; Pultorak et al., 2017). (4) Barks typically start and end in the audible range $(\sim 12 \mathrm{kHz})$ with a peak around $20 \mathrm{kHz}$, and are broadband (as opposed to narrow), noisy calls, that are $\sim 100 \mathrm{~ms}$ in duration or less. A more in-depth discussion of USV categories and relevant spectrogram figures can be found in Kalcounis-Rueppell et al. (2018).

\section{Litter Production and Paternal Pup Retrieval Tests}

Thirty-four of the 44 pairs produced a litter within the duration of the experiment (i.e., within 90 days of pair introduction at day 0 ). For each of these pairs, birth latency (number of days between day 0 and the birth of a litter), litter size and mean pup weight 
in litter were measured on the day of birth, and proportion of litter survival to weaning (day 30) was recorded. Based on birth latency (the number of days from day 0 to the birth of a litter) and a gestation period of $\sim 32$ days (Gleason and Marler, 2010; Pultorak et al., 2017), we determined whether or not females were impregnated prior to the infidelity challenge (effects on results are examined later). On post-natal day 4 , paternal pup retrieval tests were conducted using methods similar to Frazier et al. (2006) and Gleason and Marler (2010). Briefly, the male, female and all pups were moved from the home cage into a new cage placed outside the experimental room during the test $(N=31$ pairs with pups surviving until the test on post-natal day 4). One pup was immediately randomly selected and placed in the home cage in the corner diagonal from the nest. After $90 \mathrm{~s}$, the male was returned to the cage opposite the pup and a transparent lid with small air holes was placed on the cage to aid in observation. Video recording was initiated immediately to record paternal behavior. Interactions of the male with the pup were recorded for $10 \mathrm{~min}$. We measured the latency to approach the pup, total duration spent huddling over the pup, and total duration spent licking and grooming the pup. After the trial, the female and remaining pups were returned to the home cage.

\section{Statistical Analyses}

Statistical analyses were performed in SPSS version 23 and graphs were produced using Graphpad Prism 5 (La Jolla, CA, USA). Due to technical failures or experimenter error, sample sizes were decreased from 44 to 43 pairs for the pair development phase (day 7), 43 pairs for behavioral analysis and 39 pairs for USV analysis for the pair reunion phase (day 21), and 39 pairs for the pair reestablishment phase (day 28). Due to ubiquitous non-normality (based on Shapiro-Wilk tests) of behavioral and USV measures, non-parametric tests were used unless otherwise stated. All group comparisons were performed using MannWhitney $\mathrm{U}$ or Kruskal-Wallis $\mathrm{H}$ tests, and repeated measures comparisons within pairs across two different relationship phases (e.g., changes from day 7 to day 21) were performed using Wilcoxon signed rank tests. When no statistically significant difference was found between the two control conditions or the two infidelity conditions, we examined differences between the pooled "supergroups." To examine behavioral correlates (aggression and affiliation) of pair USVs (counts of each type), we pooled all trials across the relationship phases exclusively involving interaction of the original pairs (i.e., days $0,7,21$, and 28) and used partial correlation to control for pair effects. For pairs producing SVs, we additionally examined correlations between behavior and SV features (mean call duration and mean bout size). Similarly, we used partial correlation to assess pair behavior consistency across phases and to assess whether behavior during the extra-pair interaction at day 14 corresponded to pair behavior at other phases. Spearman's rank correlation was used to examine whether pair behavior during reunion could predict paternal behavior during the pup retrieval test. We also used a binary categorical variable indicating whether or not aggression was present in a given trial (e.g., during the extra-pair interaction or during pair reunion). Associations of binary categorical variables were assessed using Chi-square tests of independence. When conducting the same analyses within each of the four social challenge conditions separately for a given measure (e.g., change in affiliation from day 7 to day 21), or conducting analogous, pairwise correlations across multiple phases (e.g., day $0 \times$ day 7 , day $7 \times$ day 21 , day $21 \times$ day 28 , day $0 \times$ day 28 , etc.), we used Bonferroni corrections to minimize Type 1 error risk due to multiple comparisons. We otherwise used two-tailed tests with a significance level of alpha $=0.05$ for all analyses.

\section{RESULTS}

\section{Impact of Pair Bonding on Pair Behavior and USVs (From Day 0 to Day 7)}

From pair introduction phase (day 0) to pair development phase (day 7), there was a decrease in aggression (Wilcoxon signed rank test, $Z=-3.18, N=43, P=0.001$; Figure 2A), but no change in affiliation $(Z=-0.59, N=43, P=0.55$; Figure 2B). Pairs produced fewer barks $(Z=-2.21, N=43, P=0.03)$ and more simple sweeps $(Z=4.50, N=43, P<0.001)$ and SV calls $(Z=1.96, N=43, P=0.05)$ on day 7 than on day 0 (Figure 2C), but showed no difference in the number of complex sweeps produced ( $Z=0.92, N=43, P=0.92$; Figure $2 \mathrm{C})$. Of the subset of pairs that produced SVs at both time periods $(N=7)$, SV mean call duration increased from day 0 to day $7(Z=2.37$, $N=7, P=0.018$; Figure 2D), but SV mean bout size did not change $(Z=-0.52, N=7, P=0.60$; Figure 2E).

\section{Behavioral Correlates of USVs Within Pairs}

Across all trials involving pair interaction, barks were positively correlated with aggression $\left(r_{p}=0.22, N=165, P=0.004\right.$; Figure 3A) and negatively correlated with affiliation $\left(r_{p}=-0.17\right.$, $N=165, P=0.029$; Figure 3B). Simple sweeps were negatively correlated with aggression $\left(r_{p}=-0.22, N=165, P=0.006\right.$; Figure $3 C)$ and positively correlated with affiliation $\left(r_{p}=0.49\right.$, $N=165, P<0.001$; Figure 3D). Complex sweeps did not correlate with either affiliation or aggression ( $P$-values $\geq 0.57$ ). SVs positively correlated with affiliation $\left(r_{p}=0.44, N=165\right.$, $P<0.001$; Figure 3E), but did not correlate with aggression $\left(r_{p}\right.$ $=-0.06, N=165, P=0.47)$. Among pairs that produced SVs, $\mathrm{SV}$ mean bout size positively correlated with affiliation $\left(r_{p}=\right.$ $0.25, N=82, P=0.03$; Figure 3F) but not with aggression $\left(r_{p}\right.$ $=-0.16, N=82, P=0.17)$, while SV mean call duration did not significantly correlate with affiliation $\left(r_{p}=-0.06, N=82\right.$, $P=0.61$ ) or aggression (although there was a non-significant negative tendency; $\left.r_{p}=-0.19, N=82, P=0.09\right)$.

The presence of aggression was relatively rare (28 of 165 trials: nine for female infidelity pair trials, seven for male infidelity pair trials, nine for separation control pair trials, three for noseparation control pair trials). The presence of aggression was positively associated with the presence of barks $\left(\chi^{2}=38.6\right.$, $N=165, P<0.001)$ but not associated with the presence of simple sweeps $\left(\chi^{2}=0.89, P=0.35\right)$, complex sweeps $\left(\chi^{2}=0.66\right.$, $P=0.42)$ or SVs $\left(\chi^{2}=0.001, P=0.97\right)$. Specifically, of 165 trials, aggression was observed in $71 \%$ of trials in which barks were produced (12 of 17 trials), but only $11 \%$ of trials in which barks were not produced (16 of 148 trials). 

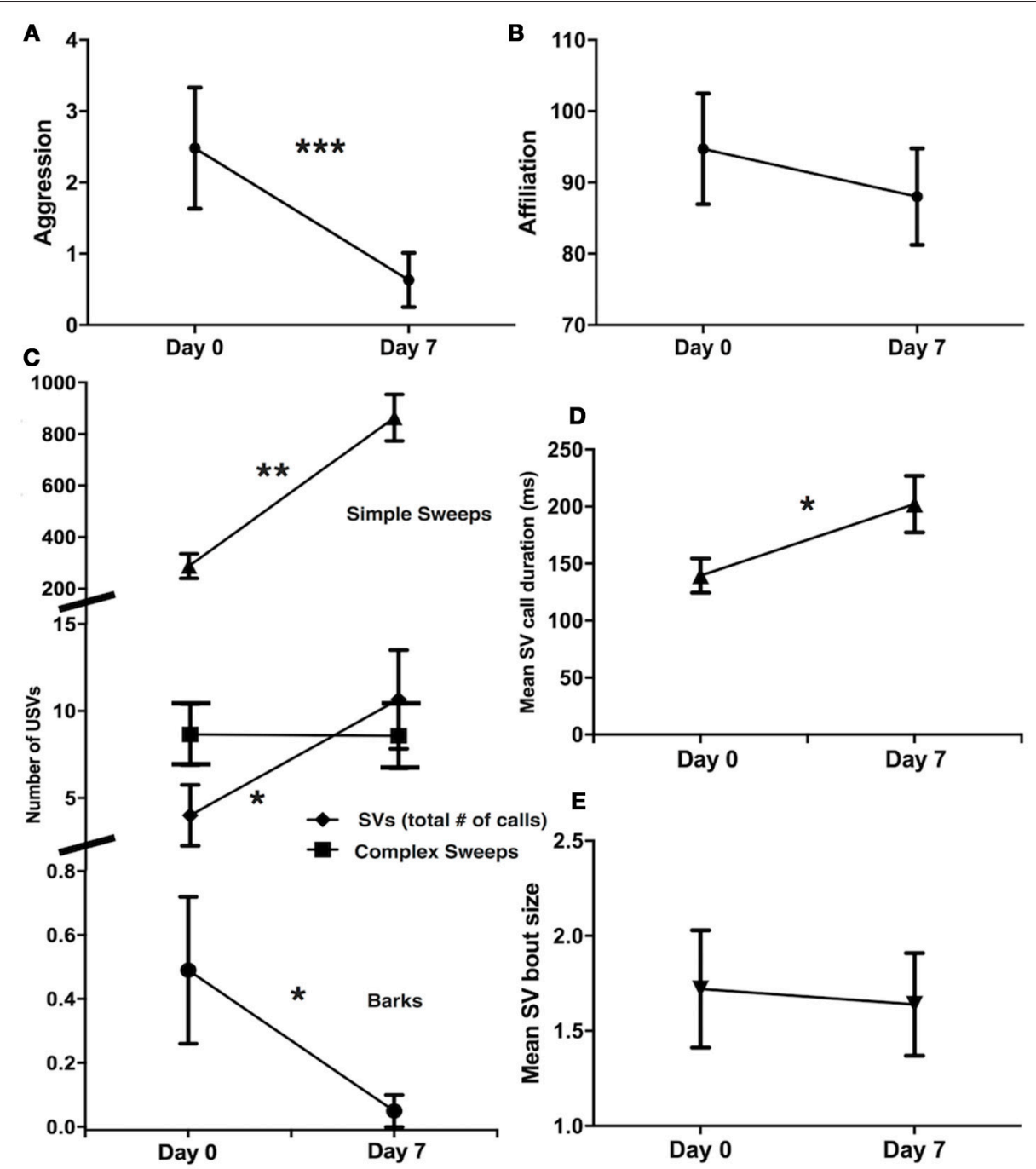

FIGURE 2 | Changes in aggression and USVs from pair introduction (day 0) to pair development (day 7). (A) Decrease in aggression ( $N=43$ ). (B) No change in affiliation $(N=43)$. (C) Decrease in barks, increase in simple sweeps and SVs, no change in complex sweeps $(N=43)$. (D) Increase in mean SV call duration ( $N=7)$. (E) No change in mean SV bout size $(N=7)$. Mean \pm standard error shown, Wilcoxon signed rank tests, ${ }^{\star} P<0.05,{ }^{\star \star} P<0.01,{ }^{\star \star \star} P<0.001$.

\section{Impact of Infidelity Challenge on Pair Behavior and USVs (During Pair Reunion on Day 21)}

There were no differences across the four social challenge conditions in affiliation (Kruskal Wallis test, $H=3.86$, $d f=3, P=0.28)$, aggression $(H=5.42, d f=3$, $P=0.14$ ), or any USV type (all $P$-values $\geq 0.16$ ). Using the repeated measures design, we determined whether pairs showed behavioral or USV changes from day 7 to day 21 (i.e., pre- to post- social challenge treatment) within each social challenge condition (results presented in Table 1). Although there were patterns toward increased SVs in the separation control condition and female infidelity condition upon reunion, no changes in USVs or behavior were statistically significant (Table 1, all $P$-values $\geq 0.02$, Bonferroni corrected alpha $=0.002$ ).
Effects of the infidelity challenge, however, were apparent when comparisons of infidelity and control supergroups were made. The infidelity supergroup showed an increase in aggression [Wilcoxon signed rank test, $Z=0.99, N=21$, $P=0.05$; Figure 4A) and barks $(Z=2.38, N=20, P=0.018$; Figure $4 \mathrm{C})$, but not affiliation $(P=0.32)$ or any other USV type (all $P$-values $\geq 0.06$ )] from day 7 to day 21 . Conversely, the control supergroup showed an increase in affiliation $(Z=1.98$, $N=22, P=0.048$; Figure 4B) and in SVs $(Z=2.27, N=19$, $P=0.02$; Figure 4D), but not aggression $(P=0.85)$ or any other USV type (all $P$-values $\geq 0.11$ ) from day 7 to day 21 . Similarly, a direct comparison of supergroups at day 21 revealed a nonsignificant tendency for increased aggression (Mann Whitney $U$ test, $\left.U=174, N_{i}=22, N_{c}=21, P=0.054\right)$ and barks $(U=141$, $\left.N_{i}=19, N_{c}=20, P=0.065\right)$ among infidelity challenge pairs as compared to control pairs, but no difference in affiliation 

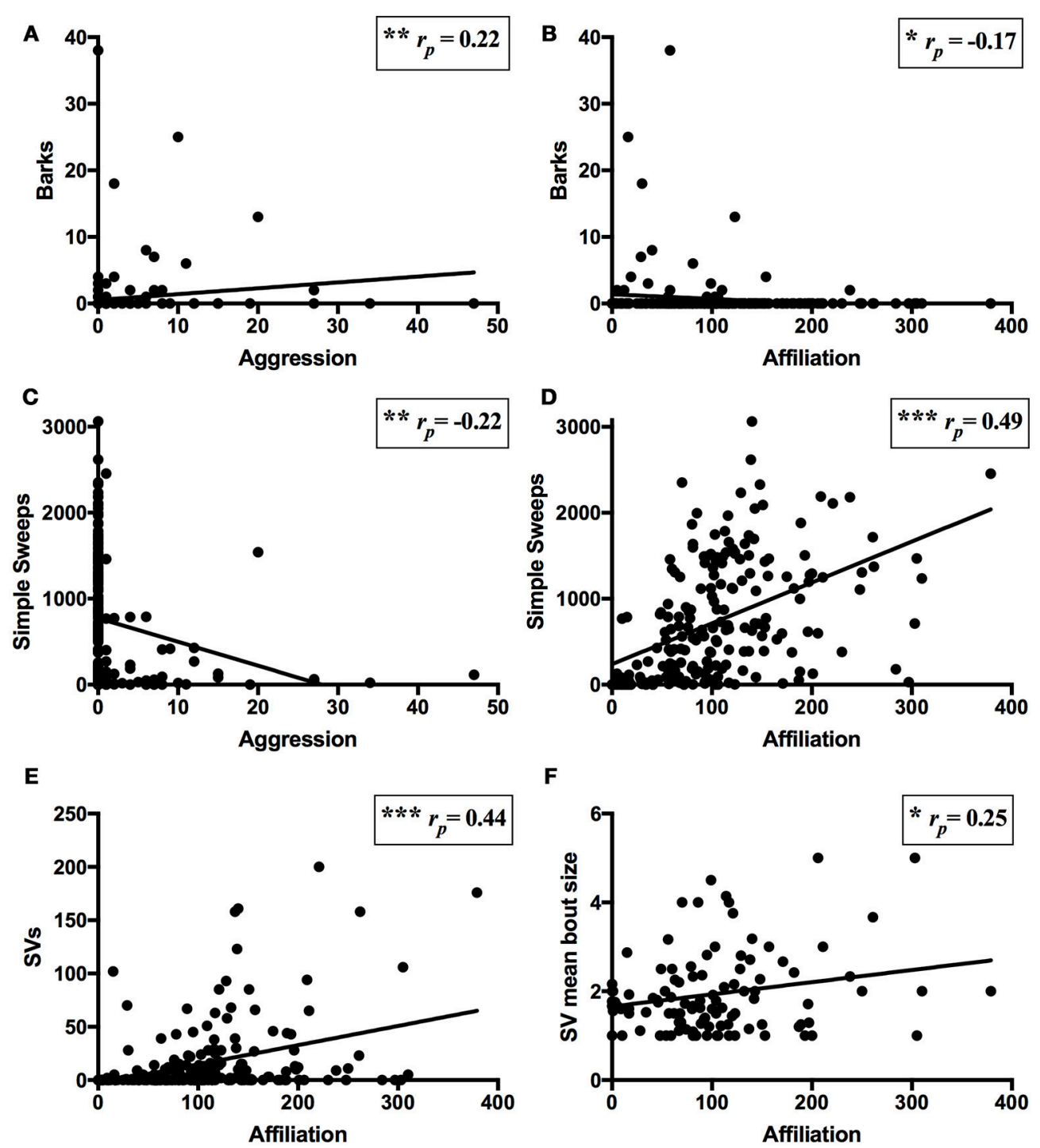

FIGURE 3 | Associations of USVs and pair behavior. Partial correlation (controlling for pair effects) between USVs and behavior for all trials within pairs over the course of the experiment $[N=165$ for (A-E), $N=82$ for (F)]. (A) Positive correlation of barks and aggression (i.e., chases and wrestles). (B) Negative correlation of barks and affiliation (i.e., approaches, follows, and sniffs). (C) Negative correlation of simple sweeps and aggression. (D) Positive correlation of simple sweeps and affiliation. (E) Positive correlation of SVs and affiliation. (F) Positive correlation of SV mean bout size and affiliation among trials in which SVs were produced. Lines of best fit shown. ${ }^{\star} P<0.05,{ }^{\star \star} P<0.01,{ }^{\star \star \star} P<0.001$

( $\left.U=195, N_{i}=22, N_{c}=21, P=0.39\right)$ or any other USV type (all $P$-values $\geq 0.22$ ).

\section{Pair Behavior Consistency and Lack of Long Lasting Effects of Infidelity Challenges}

There were no differences in affiliation or aggression (KruskalWallis tests, all $P$-values $\geq 0.46$ ) or USV counts across the four social challenge conditions (all $P$-values $\geq 0.34$ ) on day 28. Similarly, there were no differences across supergroups in affiliation or aggression (all $P$-values $\geq 0.79$ ) or USVs (all $P$-values $\geq 0.38$ ) on day 28 (pair establishment phase). Partial correlations for pair behavior across the relationship phases indicated patterns of behavioral consistency across the phases. Affiliation at day 28 positively correlated with affiliation at day $0\left(r_{p}=0.52, N=39\right.$, $P=0.001)$ and day $7\left(r_{p}=0.69, N=39, P<0.001\right)$, and aggression at day 7 positively correlated with aggression at day 0 $\left(r_{p}=0.53, N=39, P=0.001\right)$ and day $28\left(r_{p}=0.91, N=39, P<\right.$ 0.001 ), but no other correlations for behavior across phases were statistically significant (all $P$-values $>0.003$, Bonferroni corrected alpha $=0.002$ ). However, dyad behavior during the extra-pair interaction on day 14 did not correspond to pair behavior during any other phase $(N=21$, all $P$-values $\geq 0.17$, Bonferroni corrected alpha $=0.003$ ). Similarly, the presence of aggression (i.e., wrestles or chasing observed in trial) during extra-pair interaction on day 


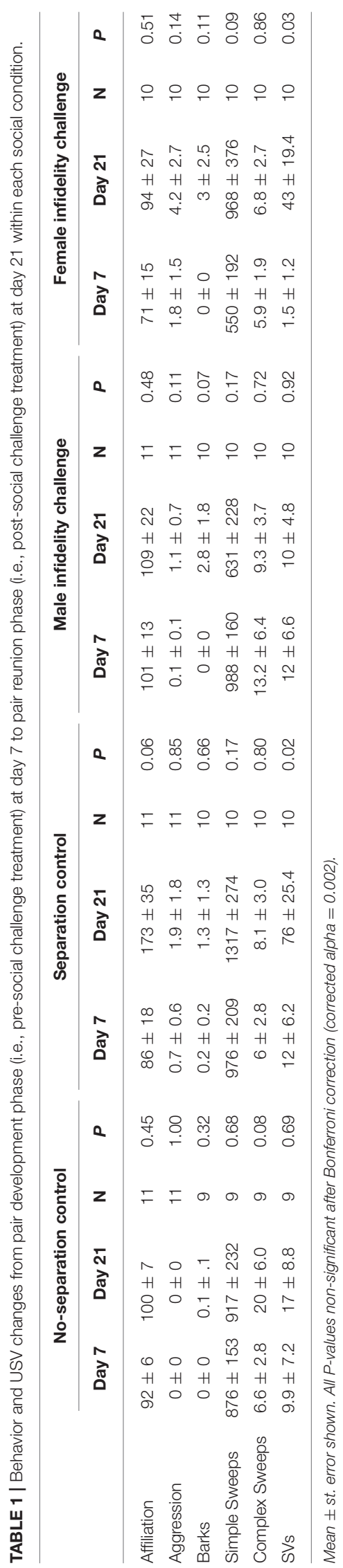

14 was not associated with the presence of aggression during pair reunion on day $21\left(\chi^{2}=0.88, N=21, P=0.35\right.$, Figure $\left.5 \mathrm{~A}\right)$ nor any other phase (all $P$-values $>0.36$ ).

\section{Using Birth Latency to Estimate Timing of Pregnancy}

Thirty four of 44 pairs produced a litter by the end of the experiment. Based on a gestation period of 32 days (Gleason and Marler, 2010; Pultorak et al., 2017), 22 of the females were estimated to have been impregnated prior to the infidelity challenge (i.e., pregnant prior to day 14), two were impregnated during the social challenge period, and 10 were impregnated after reunion with the partner. There was no significant difference in the likelihood to become pregnant prior to the infidelity challenge period across the four social challenge conditions $\left(\chi^{2}=1.82 N=44, P=0.61\right)$ or across the control and infidelity supergroup $\left(\chi^{2}=1.46, N=44, P=0.23\right)$. Of the two females impregnated during the social challenge period, one was from the no separation control and the other was from the female infidelity condition, indicating at least one case of extra-pair copulation.

\section{Long Lasting Effects of Infidelity Challenge: Predicting Reproductive Success}

Thirty-one of the 34 pairs with pups (all first time parents) successfully raised them until paternal testing day (post-natal day 4). There was no difference in the likelihood to produce a litter $\left(\chi^{2}=1.55, N=44, P=0.67\right)$ or successfully raise pups surviving to paternal testing day $\left(\chi^{2}=2.07, N=44, P=0.56\right)$ across the four social challenge conditions. There were no significant differences between the control supergroup and the infidelity supergroup in the likelihood to produce a litter $\left(x^{2}=0.52\right.$ $N=44, P=0.47$ ), any aspect of litter production (birth latency, litter size, mean pup weight; Mann Whitney $U$-tests, all $P$-values $\geq 0.36$ ) or any measures of paternal care (differences in latency to approach pup, duration of huddling over pup, or duration of licking and grooming pup; all $P$-values $\geq 0.11$ ). Finally, there were no differences in litter production or paternal care between the two infidelity conditions (male infidelity vs. female infidelity; all $P$-values $\geq 0.44$ ).

Reproductive success, as measured by aspects of litter production and paternal behavior, was predicted by pair behavior during the pair reunion phase (i.e., day 21). Pairs that successfully produced and raised offspring $(N=31)$ showed less aggression at day 21 (Mann Whitney $U$-test, $U=108, P=0.003$, Figure 5B) than pairs that did not $(N=12)$, although there was no difference in affiliation $(U=149, P=0.33)$. Among pairs from the infidelity supergroup, paternal behavior was positively predicted by pair affiliation and negatively predicted by pair aggression at day 21 . Specifically, pair affiliation was negatively correlated with the latency to contact the pup (i.e., high affiliation corresponded to fast paternal contact of pup) (Spearman's rank correlation, $r_{s}=$ $-0.59, N=14, P=0.025$, Figure $5 \mathrm{C}$ ), but did not correlate with huddling duration over the pup or licking and grooming $(P$ values $>0.34, N=14)$. Similarly, pair aggression at day 21 was negatively correlated with huddling duration over the pup $r_{s}=$ 

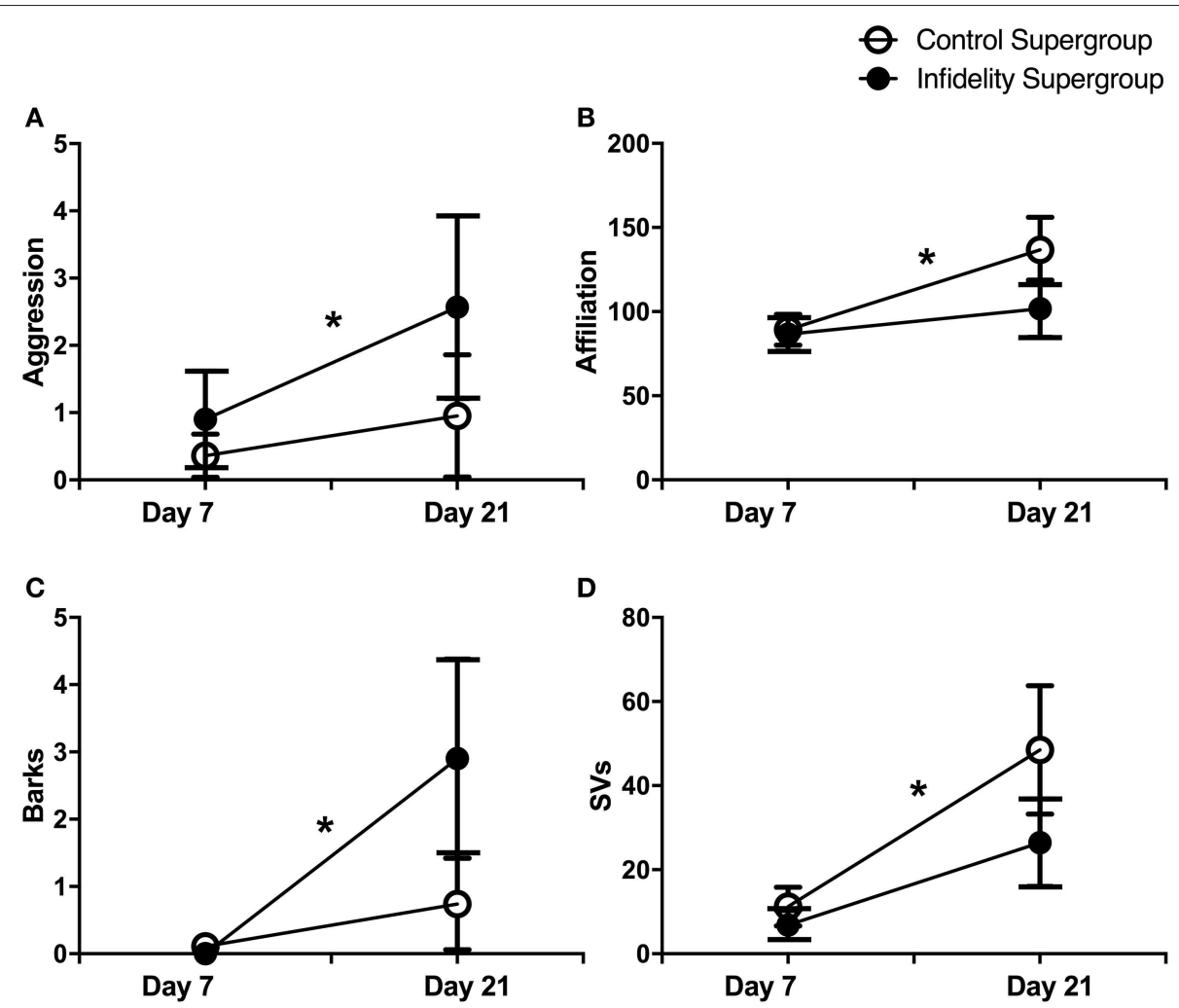

FIGURE 4 | Impacts of social challenge on pair behavior and USVs. Changes in aggression and USVs from pair development (day 7; pre-social challenge treatment) to pair reunion (day 21; post-social challenge treatment) shown for "control supergroup" (i.e., separation and no-separation control pairs pooled) and "infidelity supergroup" (i.e., male infidelity challenge and female infidelity challenge pairs pooled). (A) Increase in aggression for the infidelity supergroup ( $N=21)$, but no change for the control supergroup ( $N=22)$. (B) Increase in affiliation for the control supergroup $(N=22)$ but no change for the infidelity supergroup ( $N=21)$. (C) Increase in barks for the infidelity supergroup $(N=20)$ but no change for the control supergroup $(N=19)$. (D) Increase in SVs for the control supergroup $(N=19)$, but no change for the infidelity supergroup $(N=20)$. Wilcoxon signed rank tests, ${ }^{\star} P \leq 0.05$.

$-0.56, N=14, P=0.038)$, but did not correlate with the latency to contact the pup or with licking and grooming $(P$-values $>0.47$, $N=14)$. In contrast, among the control supergroup $(N=17)$, no paternal behaviors were correlated with affiliation (all $P$-values $>0.21, N=17$ ) or aggression (all $P$-values $>0.23, N=17$ ) during reunion (Figure 5D).

\section{DISCUSSION}

The present study contributes to our understanding of mechanisms of mammalian monogamy by characterizing changes in USVs and social behavior of pairs of California mice as they formed pair bonds and in response to a social challenge to that pair bond. This provides a valuable addition to our understanding of how USVs can change as two individuals form a strong bond and suggests that there may be specific USVs involved in maintaining pair bonds. In addition, even though the infidelity challenge lasted for one out of the 4 weeks of the study and temporarily disrupted the established normal pair bond behavior through an increase in aggressive USVs and behavior, there was no direct effect on pair reproductive success in this highly monogamous species. However, aggression during reunion after the social challenge was associated with lower reproductive success. Pairs with higher aggression levels upon reunion showed a lower likelihood of successfully producing a litter, and among pairs that experienced the infidelity challenge, paternal behavior was positively predicted by pair affiliation and negatively predicted by pair aggression upon reunion with the original partner (maternal behavior was not measured). We speculate that pairs vary in their resilience to social challenges, such as that of the infidelity challenge, and this resilience influences reproductive success.

\section{Behavior and USV Changes Associated With the Formation of a Pair Bond}

The longitudinal design of the present study (Figure 1) allowed us to characterize changes resulting from the pair bonding process. As bonds formed, pairs expressed decreased aggression (chases and wrestles) and bark USVs (Figure 2), and although there was no change in affiliation (approaches, follows, and sniffs), the pairs expressed more simple sweeps, SV calls, and longer SV call durations (Figure 2). Simple sweeps, SV calls and SV call duration may therefore be USVs for pair bond maintenance, as discussed below. 

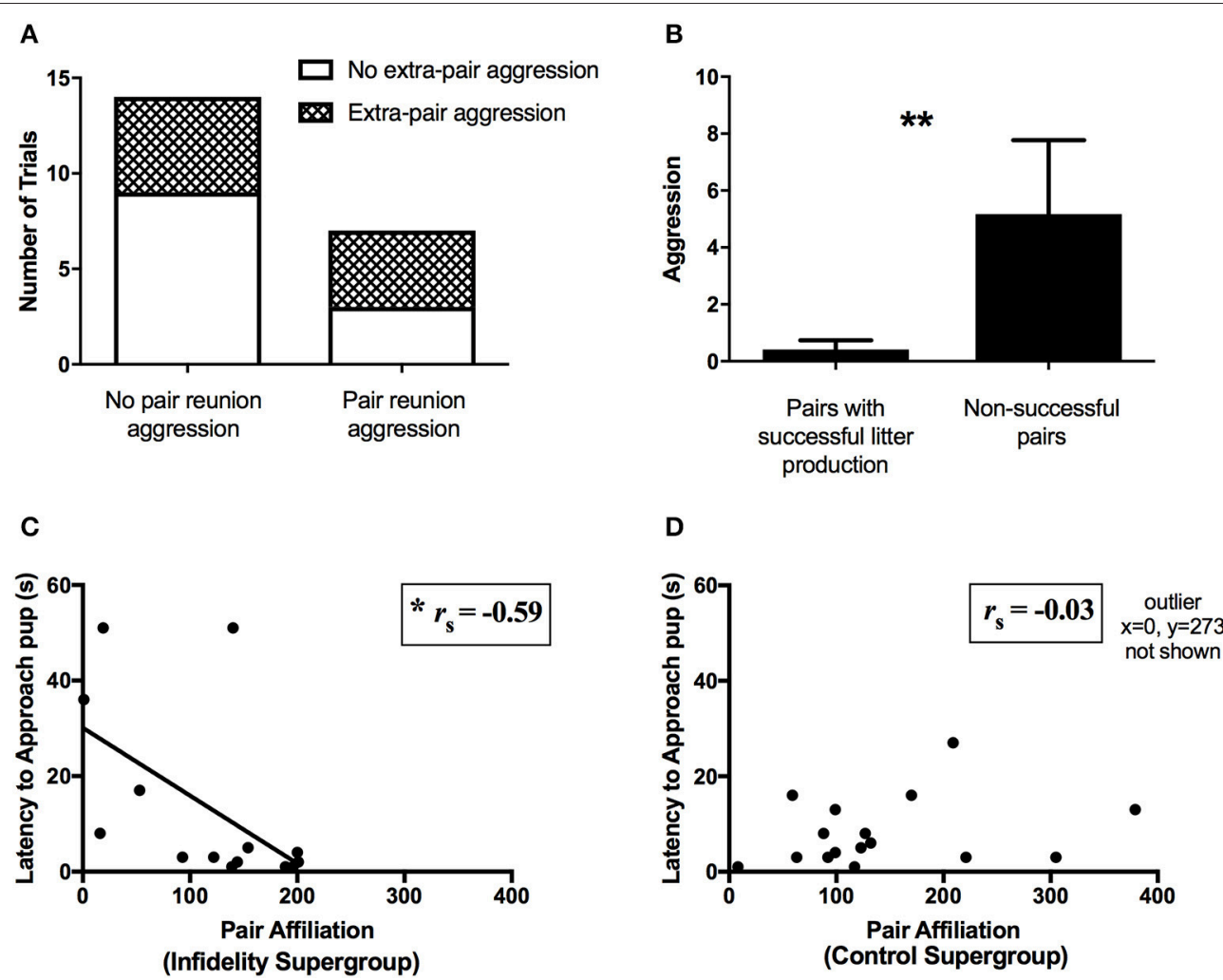

FIGURE 5 | Predictors of pair reproductive success. (A) No association between presence of aggression during the extra-pair interaction at day 14 and presence of aggression at pair reunion on day 21 (Chi square test of independence, $N=21, P=0.35$ ). (B) Pairs that successfully produced a litter (i.e., had pups and the pups survived to testing day on post-natal day $4, N=31$ ) showed less aggression at pair reunion than pairs who did not successfully produce a litter ( $N=12)($ Mann Whitney test, ${ }^{\star \star} P<0.01$ ). (C) Among the infidelity supergroup, pair affiliation at pair reunion was negatively correlated with latency to contact pup (i.e., high affiliation corresponded to fast paternal contact of pup) (Spearman's rank correlation, $\left.N=14, P=0.025,{ }^{\star} P<0.05\right)$. (D) Conversely, among the control supergroup, pair affiliation was not correlated with latency to contact pup (Spearman's rank correlation, $N=17, P=0.91$ ).

We predicted an increase of both SV calls and complex sweeps in bonded pairs, given previously observed production of SV calls in the field among bonded pairs (Briggs and Kalcounis-Rueppell, 2011) and associations of complex sweeps with pair affiliation in the laboratory (Pultorak et al., 2017), but only found support for the former and not the latter (see discussion below). Simple sweeps also increased as a result of bonding, and interestingly, although not statistically comparable, pair bonded males in a previous study produced fewer simple sweeps than did naïve (non-paired) males in response to novel females (Pultorak et al., 2015), suggesting that state changes as a result of bonding are manifest differently in intra-pair vs. extra-pair contexts. Changes in USV subtypes in response to bonding are broadly consistent with vocal repertoire and syntax changes concordant with pairing observed in socially monogamous birds (Hall, 2009) and primates (Snowdon and Elowson, 1999; Geissmann, 2002).

\section{Associations Between USV Types and Pair Behavior}

Simple sweeps and SVs (but not complex sweeps) emerged as indicators of pair affiliation, whereas barks emerged as indicators of aggression (Figure 3). Simple sweeps occurred in almost all trials of the experiment, but totals increased as a result of pair bonding and were associated with a suite of affiliative behaviors (approaches, following, and sniffing). This finding supports the broad concept of a positive or "approach," as opposed to "avoidant" (O'Connell and Hofmann, 2011) social behavioral role for simple sweeps. This finding also indirectly supports previous indications of a possible role for this vocal type in courtship since pair bonded males produce fewer simple sweeps compared to non-bonded males in response to extra-pair females in response to testosterone injection just prior to interaction (Pultorak et al., 2015). Minimally, simple sweep production appears to broadly indicate attraction toward the mate and may be associated with pair bond maintenance.

The number of SVs produced and SV mean call duration similarly increased as a result of pair bonding, but interestingly, SV mean bout size did not change (Figure 2). We predicted an increase in bout size given a field study indicating bouts of three calls (i.e., 3SVs) were more likely to occur when individuals were in the presence of a conspecific, whereas 1SVs were more likely to occur in isolation in the field (Briggs and KalcounisRueppell, 2011). Consistent with the field study, we found that SV mean bout size positively correlated with affiliation (Figure 3) 
but not with aggression. Rather than increasing the bout size, pairs seem to be lengthening each call (i.e., "syllable") as the pair bond forms (Figure 2). This pattern is consistent with previous work revealing a positive correlation between female interest in the playback of her mate's calls and the SV mean call duration of those calls (Pultorak et al., 2017). Likewise, among same-sex dyads, short SV call durations (i.e., closer to the durations of bark calls) are predictive of the intensity of aggression (Rieger and Marler, 2018).

Taken together, these findings reinforce the notion that changes in spectral and temporal features of the acoustic signal may inform important functional aspects of USVs between California mouse mates, akin to intersexual acoustic communication in other taxa. On a comparative level, aspects of spectral and temporal features are known to underlie "emotional states" in rats (Rattus norvegicus, Brudzynski, 2013), house mice (Mus musculus, Lahvis et al., 2011), and European starlings (Sturnis vulgaris, Alger et al., 2016). They can also signify quality in baboons (Papio cynocephalus, Fischer et al., 2004) and songbirds (Catchpole and Slater, 2008). Similarly, in Mus, USV spectral and temporal features can reflect individuality and kinship (Hoffmann et al., 2012) and these features are sensitive to changes in the social environment (Chabout et al., 2015). USVs are also used in monogamous species with pair bonds such as prairie voles (e.g., Lepri et al., 1988; Ma et al., 2014), as well as in affiliative calls by lemurs that form long-term relationships (review by Zimmermann, 2018). The trajectory of vocal change over the formation of the pair bond, however, has not been examined in these species. These studies suggest that vocalizations are indicating emotional state, at least, but have the potential to convey more complex information. Our current study has the most detailed analysis of USVs showing how USVs can change as a pair bond forms in contrast to investigating already formed pair bonds. Such studies will allow us to better understand the potential functions of each call type.

We predicted that "complex sweeps" would play a role in pair bonding since male complex sweeps predicted later affiliative behavior in a previous study (Pultorak et al., 2017). Our prediction was not supported; complex sweep production did not increase as a result of pair bonding (neither from day 0 to day 7 within all pairs nor from day 7 to day 21 within control pairs) and was not correlated with affiliation or aggression among pairs throughout the study. We can only speculate, but the previous association between complex calls and later affiliative behavior possibly occurred because calls may have been continually produced by males in the prior study involving a mesh barrier (Pultorak et al., 2017) in order to elicit approach from the female, consistent with findings in house mice (Chabout et al., 2015), whereas this was not the case when animals were able to fully interact in the present study. Another possibility is that complex sweeps might indicate a general level of behavioral arousal not unique to pair interactions. More investigation on this call type would be useful, yet difficulties arise given their comparatively rare production in the laboratory and low likelihood of being recorded by microphones in the wild because they have a very high frequency and attenuate rapidly.
Peromyscus bark calls have been identified in the wild (Kalcounis-Rueppell et al., 2006), and are readily observed during male-male and female-female aggression (Rieger and Marler, 2018). Our findings are consistent with these studies and suggest that California mice also use bark calls in male-female aggressive contexts. Overall, bark production was positively correlated with aggressive behavior and negatively correlated with affiliative behavior (Figure 3). Barks decreased during pair bond formation (Figure 2) and increased during reunion with the mate in the infidelity supergroup (Figure 4). Across all trials within pairs, aggression was observed in $71 \%$ of the trials for which barks were produced, as compared to only $11 \%$ of trials for which barks were not observed. However, the methodology of the present study did not allow us to determine the source (i.e., male or female) of the barks, so we cannot conclude whether they were primarily produced by males or females, or by aggressors or defenders. We suspect barks were produced primarily by females, and were most likely defensive, given previous findings that barks were found at higher rates in P. californicus female-female encounters than in malemale encounters, and corresponded most highly with defensive aggression (Rieger and Marler, 2018). Interestingly, one study of Siberian hamsters (Phodopus sungorus) similarly found that female-female aggressive encounters exhibited proportionally more "rattle" vocalizations than male-male aggressive encounters (Keesom et al., 2015). Analogous to the association of rattles with aggression, as opposed to other calls types in hamsters, the association of aggression with vocal behavior was unique to bark calls in $P$. californicus, as no other USV types were positively related to aggression. Indeed, the comparatively lowerfrequency (components in the auditory range, i.e., $<20 \mathrm{kHz}$ ) and "noisy" (as opposed to "narrow") character of barks and rattles is consistent with competitive and territorial vocalizations in other taxa (Bradbury and Vehrencamp, 1998).

\section{Impact of Infidelity Challenge and Isolation}

After establishing what characterizes a bonded pair, we were able to test whether an infidelity challenge would disrupt pair bonds in this highly monogamous species by examining both aggressive and affiliative behaviors, as well as changes in the USVs. Interestingly, infidelity challenges impacted behaviors less than predicted. These changes were relatively mild, only being detected by pooled analysis of infidelity conditions (i.e., supergroups), and were only temporary since they returned to "normal" levels of pair bond behavior by day 28. In fact, pair behaviors at day 28 were predicted by pair behaviors at day 7 in an analysis of all pairs. Nonetheless, the infidelity challenge treatments increased aggression and barks with partners upon reunion, whereas the isolation and no-separation treatments increased affiliative behaviors and SVs with partners upon reunion, collectively (Figure 4), suggesting that the infidelity challenge had a stunting effect on the pair bonding process. It is possible that additional behaviors characteristic to pair bonding in rodents such as huddling, grooming, or side-by-side contact (Wang and Aragona, 2004; Ophir et al., 2008; Gleason et al., 2012) were influenced by the social challenge. However, we did not make observations when such behaviors might be seen (e.g., 
during inactive hours in home cages). Our observations were limited to brief, 5-min interactions in a neutral arena.

The 1-week isolation from the mate, both physically and acoustically, had surprisingly little effect on the behaviors measured, supporting the concept that pair bonds in California mice are highly stable. A previous study in Mongolian gerbils indicated pair-disruptive behavioral effects of 1-week separation and isolation on individuals (Hendrie and Starkey, 1998) and in California mice, stress from pair separation (as little as 2 days) is presumed to occur based on detrimental effects on wound healing rates in separated pairs as compared to control pairs that maintained contact (Glasper and DeVries, 2005; Martin et al., 2006). However, pair behavior in response to separation had not been previously assessed. In the present study, separation alone was not sufficient to disrupt normal pair behavior. Direct comparison of the separation controls and noseparation controls did not reveal differences, and pooled analysis indicated that control pairs were characterized by increased affiliation from day 7 to day 21, whereas pairs undergoing the infidelity challenge did not show this pattern. The precise mechanism through which this disruption may have occurred remains unknown and is ripe for further exploration.

One factor that could theoretically influence whether infidelity challenges or isolation influences the ease with which a pair bond could be disrupted is whether the females had become pregnant, either by the original "mate" or the "extra-pair mate." We were limited in our ability to determine whether or not extrapair dyads copulated during their 1-week co-housing period, but birth latency data suggest that only one female's litter was sired by an extra-pair male. It is possible that pregnancy from the original mate could be blocked from exposure to the extra-pair male, as evidenced by the "Bruce effect" observed in rodents (Bruce, 1959), including some evidence in the closelyrelated Peromyscus maniculatus (Dewsbury, 1982), although reproductive behavior and physiology might substantially differ between the polygamous $P$. maniculatus and monogamous $P$. californicus (Insel et al., 1991). Given the similarity in copulation time based on birth latency estimates in the present study (50\% of females by day 14) to similar P. californicus studies without extra-pair housing ( $53 \%$ by day 9 , Pultorak et al., 2017; 54\% by day 12, Gleason and Marler, 2010), the Bruce effect not likely a major determinant in the present study. Further, no difference was found in likelihood to become pregnant across conditions or across supergroups. More likely, dynamics within pairs determined whether, and how fast, offspring were produced. This idea is supported by evidence in indicating a strong relationship between pair affiliation (mate preference, huddling, grooming, close proximity) and short birth latencies (Gleason and Marler, 2010; Gleason et al., 2012). Nonetheless, the resultant experience from the infidelity challenge had observable effects on pair behavior upon reunion that did not occur in controls. Aggression may have been induced by unfamiliar odors of the extra-pair individual collected on the fur of the pair mate, but this is unlikely since extra-pair odors did not alter pair behavior in a separate study (Becker and Marler, unpublished data). A more likely possibility is that re-housed individuals started to form a new pair bond with the extra-pair individual. One question that arises is whether California mice, or pair bonding species more broadly, can maintain multiple pair bonds simultaneously. Our implicit assumption was that the creation of a new bond would disrupt an old bond, but this may not necessarily be the case.

Classical sociobiological theory posits that there would be sex differences in response to threats to sexual fidelity (Trivers, 1972; Westneat et al., 1990; Clutton-Brock and Vincent, 1991). Fidelity may be actively imposed via mate guarding and harassment of the partner in both sexes (Wittenberger and Tilson, 1980), but males are expected to suffer greater fitness costs from partner infidelity due to paternity uncertainty (Trivers, 1972). Aggression might thus be predicted to be higher in cases of female infidelity over cases of male infidelity, but this was not found in the present study. Since we did not test paternity, we cannot definitively determine effects of paternal uncertainty. Interestingly, photoperiod-mediated infanticide inhibition can be triggered by ejaculation alone, at least in house mice (M. musculus; Perrigo et al., 1990), which could theoretically influence paternal behavior. Paternal behavior also might be influenced through the loss of a bond with the female partner. Although it cannot be ruled out, it is unlikely that paternity uncertainty played a major role in pup retrieval outcomes. If paternity uncertainty was negatively influencing paternal care, one might predict decreased paternal investment among potentially cuckolded males, but there were no significant differences in any measure of litter production or paternal care between the male infidelity and female infidelity conditions. It has been suggested that less behavioral sexual dimorphism should exist in monogamous species (Kleiman, 1977). Indeed, we found no significant differences in behavior or USVs in comparisons of female infidelity vs. male infidelity conditions at pair reunion (day 21).

Results from the present study suggest that resilience to an infidelity stressor is indicative of pair compatibility and may be associated with meaningful fitness benefits. A previous study in California mice revealed that pairings of "preferred" partners resulted in reproductive success increases over pairings of "nonpreferred" partners (Gleason et al., 2012). The present study used randomized, forced pairings resulting in variation in pair compatibility. It is possible that if we had let individuals choose their mates instead of creating forced pairings that pair resilience to social challenges would have been even greater. Notably, variability in response to the infidelity challenge was predictive of reproductive success measures. Seven of the 21 pairs (33\%) subjected to the infidelity challenge exhibited aggression at pair reunion at day 21 (as compared to 2 of 20 control pairs), and this aggression was associated with lowered reproductive success (Figure 5). Further, aggression at pair reunion was not associated with aggression during extra-pair interaction (day 14), indicating that aggressive behaviors were particular to dyads, not simply due to one aggressive individual across multiple contexts (Figure 5). Aggressive pairs at day 21 showed a longer birth latency than non-aggressive pairs (Figure 5), and paternal behavior (via latency to contact his pup) was negatively associated with the level of aggression at day 21, at least among pairs subjected to the infidelity challenge. Conversely, pair affiliation at day 21 was positively associated with paternal approach to the 
pup (Figure 5). These effects are not trivial, given the strong link between fast and consistent production of litters (averaging over two litters per breeding season) and reproductive success in the wild (Ribble, 1992) as well as the importance of paternal care in this species (Cantoni and Brown, 1997; Gubernick and Teferi, 2000).

In conclusion, we characterized behavioral and acoustic changes during the development of a pair bond and in response to an infidelity challenge. We identified that simple sweeps and SV vocalizations were associated with affiliation, while bark vocalizations were associated with aggression, suggesting a role for acoustic changes in the formation and maintenance of rodent pair bonds. The current study reinforced the concept of the robustness of pair bonds in this strictly monogamous species (Ribble, 1991; Gubernick and Nordby, 1993). Even in this highly monogamous species, however, a social perturbation involving an extra-pair conspecific had the capacity to alter normal pair bond interactions. We speculate that pair resilience to a stressor or challenge may be indicative of pair bond quality and suggest that future studies further investigate this possibility. In a recent comprehensive meta-analysis of 81 studies on divorce (i.e., mate switching, typically between breeding seasons) in socially monogamous bird species, Culina et al. (2015) conclude that divorce is an adaptive response to low breeding success. However, one survey of monogamous mammal species failed to detect a significant impact of pair bond strength on rates of extra-pair paternity (Huck et al., 2014). Calls have been made for more experimental methods in this area across taxa (Uller and Olsson, 2008). A strength of the present study is that

\section{REFERENCES}

Alger, S. J., Larget, B. R., and Riters, L. V. (2016). A novel statistical method for behaviour sequence analysis and its application to birdsong. Anim. Behav. 116, 181-193. doi: 10.1016/j.anbehav.2016.04.001

Atkins, D. C., Baucom, D. H., and Jacobson, N. S. (2001). Understanding infidelity: correlates in a national random sample. J. Fam. Psychol. 15, 735-749. doi: 10.1037/0893-3200.15.4.735

Bosch, O. J., Nair, H. P., Ahern, T. H., Neumann, I. D., and Young, L. J. (2009). The CRF system mediates increased passive stress-coping behavior following the loss of a bonded partner in a monogamous rodent. Neuropsychopharmacology 34, 1406-1415. doi: 10.1038/npp.2008.154

Bradbury, J. W., and Vehrencamp, S. L. (1998). Principles of Animal Communication. Sunderland, MA: Sinauer Associates, Inc.

Briggs, J. R., and Kalcounis-Rueppell, M. C. (2011). Similar acoustic structure and behavioural context of vocalizations produced by male and female California mice in the wild. Anim. Behav. 82, 1263-1273. doi: 10.1016/j.anbehav.2011.09.003

Bruce, H. M. (1959). An exteroceptive block to pregnancy in the mouse. Nature 184:105. doi: $10.1038 / 184105 \mathrm{a} 0$

Brudzynski, S. M. (2013). Ethotransmission: communication of emotional states through ultrasonic vocalization in rats. Curr. Opin. Neurobiol. 23, 310-317. doi: 10.1016/j.conb.2013.01.014

Brudzynski, S. M. (ed.) (2018). Handbook of Ultrasonic Vocalization: A Window into the Emotional Brain, Vol. 25. London, UK: Academic Press; HBBN.

Cantoni, D., and Brown, R. (1997). Paternal investment and reproductive success in the California mouse, Peromyscus californicus. Anim. Behav. 54, 377-386. doi: 10.1006/anbe.1996.0583

Catchpole, C. K., and Slater, P. J. B. (2008). Bird Song: Biological Themes and Variations. Cambridge: Cambridge University Press. it examines pair bond strength in relation to extra-pair activity by presenting a controlled social challenge manipulation in an animal model of monogamy that may not be feasible in field studies.

\section{AUTHOR CONTRIBUTIONS}

JP, CM, SA, and SL contributed to experimental design. AJ was critical in contributing to programming the software used in detection and recognition of ultrasonic vocalizations. JP and SA conducted statistical analyses. JP, CM, and SA contributed to manuscript writing.

\section{ACKNOWLEDGMENTS}

We thank C. Hupp, K. Matusinec, A. Ehlers, S. Parker, W. Arrett, A. Mueller, and A. Bird for assistance with data collection and Z. Miller for assistance with preparing code used in USV analysis. We also thank Charles Snowden for reading and commenting on the manuscript. This study was funded by the Lowell $\mathrm{E}$ and Ruth Chase Noland Memorial Fund through the Department of Zoology, University of Wisconsin-Madison, and NSF IOS1355163.

\section{SUPPLEMENTARY MATERIAL}

The Supplementary Material for this article can be found online at: https://www.frontiersin.org/articles/10.3389/fevo. 2018.00125/full\#supplementary-material

Chabout, J., Sarkar, A., Dunson, D. B., and Jarvis, E. D. (2015). Male mice song syntax depends on social contexts and influences female preferences. Front. Behav. Neurosci. 9:76. doi: 10.3389/fnbeh.2015. 00076

Choudhury, S. (1995). Divorce in birds: a review of the hypotheses. Anim. Behav. 50, 413-429. doi: 10.1006/anbe.1995.0256

Clutton-Brock, T. H., and Vincent, A. C. (1991). Sexual selection and the potential reproductive rates of males and females. Nature 351, 58-60. doi: $10.1038 / 351058 \mathrm{a} 0$

Culina, A., Radersma, R., and Sheldon, B. C. (2015). Trading up: the fitness consequences of divorce in monogamous birds. Biol. Rev. 90, 1015-1034. doi: 10.1111/brv.12143

Dewsbury, D. A. (1982). Pregnancy blockage following multiple-male copulation or exposure at the time of mating in deer mice, Peromyscus maniculatus. Behav. Ecol. Sociobiol. 11, 37-42. doi: 10.1007/BF00297664

Dewsbury, D. A. (1988). Comparative Perspective in Modern Psychology. Lincoln, NE: University of Nebraska Press.

Dietrich-Bischoff, V., Schmoll, T., Winkel, W., Krackow, S., and Lubjuhn, T. (2006). Extra-pair paternity, offspring mortality and offspring sex ratio in the socially monogamous coal tit (Parus ater). Behav. Ecol. Sociobiol. 60, 563-571. doi: 10.1007/s00265-006-0201-5

Dudley, D. (1974). Paternal behavior in the California mouse, Peromyscus californicus. Behav. Biol. 11, 247-252. doi: 10.1016/S0091-6773(74)9 0433-7

Emlen, S. T., and Oring, L. W. (1977). Ecology, sexual selection, and the evolution of mating systems. Science 197, 215-223. doi: 10.1126/science. 327542

Fernandez-Duque, E., Mason, W. A., and Mendoza, S. P. (1997). Effects of duration of separation on responses to mates and strangers in the monogamous titi monkey (Callicebus moloch). Am. J. Primatol. 43, 225-237. doi: 10.1002/ (SICI)1098-2345(1997)43:3<225::AID-AJP3>3.0.CO;2-Z 
Fischer, J., Kitchen, D. M., Seyfarth, R. M., and Cheney, D. L. (2004). Baboon loud calls advertise male quality: acoustic features and their relation to rank, age, and exhaustion. Behav. Ecol. Sociobiol. 56, 140-148. doi: 10.1007/s00265-003-0739-4

Fletcher, G. J., Simpson, J. A., Campbell, L., and Overall, N. C. (2015). Pairbonding, romantic love, and evolution: the curious case of Homo sapiens. Perspect. Psychol. Sci. 10, 20-36. doi: 10.1177/1745691614561683

Frazier, C. R. M., Trainor, B. C., Cravens, C. J., and Marler, C. A. (2006). Paternal retrieving behavior of California mice increases both aggression and vasopressin immunoreactive staining in their male offspring. Horm. Behav. 50, 699-707. doi: 10.1016/j.yhbeh.2006.06.035

Geissmann, T. (2002). Duet-splitting and the evolution of gibbon songs. Biol. Rev. Camb. Philos. Soc. 77, 57-76. doi: 10.1017/S1464793101005826

Geissmann, T., and Orgeldinger, M. (2000). The relationship between duet songs and pair bonds in siamangs, Hylobates syndactylus. Anim. Behav. 60, 805-809. doi: 10.1006/anbe.2000.1540

Ginther, A. J., Ziegler, T. E., and Snowdon, C. T. (2001). Reproductive biology of captive male cottontop tamarin monkeys as a function of social environment. Anim. Behav. 61, 65-78. doi: 10.1006/anbe.2000.1587

Glasper, E. R., and DeVries, A. C. (2005). Social structure influences effects of pair-housing on wond healing. Brain Behav. Immun. 19, 61-68. doi: 10.1016/j.bbi.2004.03.002

Gleason, E. D., Holschbach, M. A., and Marler, C. A. (2012). Compatibility drives female preference and reproductive success in the monogamous California mouse (Peromyscus californicus) more strongly than male testosterone measures. Horm. Behav. 61, 100-107. doi: 10.1016/j.yhbeh.2011.10.009

Gleason, E. D., and Marler, C. A. (2010). Testosterone response to courtship predicts future paternal behavior in the California mouse, Peromyscus californicus. Horm. Behav. 57, 147-154. doi: 10.1016/j.yhbeh.2009.10.006

Griffith, S. C., Owens, I. P. F., and Thuman, K. A. (2002). Extra pair paternity in birds: a review of interspecific variation and adaptive function. Mol. Ecol. 11, 2195-2212. doi: 10.1046/j.1365-294X.2002.01613.x

Gubernick, D. J., and Alberts, J. R. (1987). The biparental care system of the California mouse, Peromyscus californicus. J. Comp. Psychol. 101:169. doi: $10.1037 / 0735-7036.101 .2 .169$

Gubernick, D. J., and Nordby, J. C. C. (1993). Mechanisms of sexual fidelity in the monogamous California mouse, Peromyscus californicus. Behav. Ecol. Sociobiol. 32, 211-219. doi: 10.1007/BF00173779

Gubernick, D. J., and Teferi, T. (2000). Adaptive significance of male parental care in a monogamous mammal. Proc. R. Soc. Lond. B 267, 147-150. doi: $10.1098 / \mathrm{rspb} .2000 .0979$

Hall, M. L. (2009). A review of vocal duetting in birds. Adv. Study Behav. 40, 67-121. doi: 10.1016/S0065-3454(09)40003-2

Hendrie, C. A., and Starkey, N. J. (1998). Pair-bond disruption in Mongolian gerbils: effects on subsequent social behaviour. Physiol. Behav. 63, 895-901. doi: 10.1016/S0031-9384(98)00005-5

Hoffmann, F., Musolf, K., and Penn, D. J. (2012). Spectrographic analyses reveal signals of individuality and kinship in the ultrasonic courtship vocalizations of wild house mice. Physiol. Behav. 105, 766-771. doi: 10.1016/j.physbeh.2011.10.011

Huck, M., Fernandez-duque, E., Babb, P., and Schurr, T., (2014). Correlates of genetic monogamy in socially monogamous mammals: insights from Azara's owl monkeys. Proc. R. Soc. Lond. B 281:20141095. doi: 10.1098/rspb.2014.0195

Insel, T. R., Gelhard, R., and Shapiro, L. E. (1991). The comparative distribution of forebrain receptors for neurohypophyseal peptides in monogamous and polygamous mice. Neuroscience 43, 623-630. doi: 10.1016/0306-4522(91)90321-E

Kalcounis-Rueppell, M. C., Metheny, J. D., and Vonhof, M. J. (2006). Production of ultrasonic vocalizations by Peromyscus mice in the wild. Front. Zool. 3:3. doi: 10.1186/1742-9994-3-3

Kalcounis-Rueppell, M. C., Petric, R., Briggs, J. R., Carney, C., Marshall, M. M., Willse, J. T., et al. (2010). Differences in ultrasonic vocalizations between wild and laboratory California mice (Peromyscus californicus). PLoS ONE 5:e9705. doi: 10.1371/journal.pone.0009705

Kalcounis-Rueppell, M. C., Pultorak, J. D., and Marler, C. A. (2018). "Ultrasonic vocalizations of mice in the genus Peromyscus," in Handbook of Ultrasonic Vocalization, Vol. 25, ed S. M. Brudzynski (London, UK: Academic Press; HBBN), 227-235.
Keesom, S. M., Rendon, N. M., Demas, G. E., and Hurley, L. M. (2015). Vocal behaviour during aggressive encounters between Siberian hamsters, Phodopus sungorus. Anim. Behav. 102, 85-93. doi: 10.1016/j.anbehav.2015.01.014

Kingsbury, M. A., Gleason, E. D., Ophir, A. G., Phelps, S. M., Young, L. J., and Marler, C. A. (2012). Monogamous and promiscuous rodent species exhibit discrete variation in the size of the medial prefrontal cortex. Brain Behav. Evol. 80, 4-14. doi: 10.1159/000339247

Kleiman, D. G. (1977). Monogamy in mammals. Q. Rev. Biol. 52, 39-69. doi: $10.1086 / 409721$

Lahvis, G. P., Alleva, E., and Scattoni, M. L. (2011). Translating mouse vocalizations: prosody and frequency modulation. Genes Brain Behav. 10, 4-16. doi: 10.1111/j.1601-183X.2010.00603.x

Lepri, J. J., Theodorides, M., and Wysocki, C. J. (1988). Ultrasonic vocalizations by adult prairie voles, Microtus ochrogaster. Experientia 44, 271-273. doi: $10.1007 / \mathrm{BF} 01941736$

Lieberwirth, C., and Wang, Z. (2016). The neurobiology of pair bond formation, bond disruption, and social buffering. Curr. Opin. Neurobiol. 40, 8-13. doi: 10.1016/j.conb.2016.05.006

Ma, S. T., Resendez, S. L., and Aragona, B. J. (2014). Sex differences in the influence of social context, salient social stimulation and amphetamine on ultrasonic vocalizations in prairie voles. Integr. Zool. 9, 280-293. doi: $10.1111 / 1749-4877.12071$

Marler, C. A., Bester-Meredith, J., and Trainor, B. C. (2003). "Paternal behavior and aggression: endocrine mechanisms and nongenomic transmission of behavior, in Advances in the Study of Behavior, eds P. J. B. Slater, J. S. Rosenblatt, C. T. Snowdon, and T. J. Roper (New York, NY: Academic Press), 263-323.

Martin, J. K., Coulson, G., Handasyde, K., and Taylor, A. (2007). Long-term pair-bonds without mating fidelity in a mammal. Behaviour 144, 1419-1445. doi: $10.1163 / 156853907782418240$

Martin, L. B., Glasper, E. R., Nelson, R. J., and Devries, A. C. (2006). Prolonged separation delays wound healing in monogamous California mice, Peromyscus californicus, but not in polygynous white-footed mice, P. leucopus. Physiol. Behav. 87, 837-841. doi: 10.1016/j.physbeh.2006.01.035

Mock, D. W., and Fujioka, M. (1990). Monogamy and long-term pair bonding in vertebrates. Trends Ecol. Evol. 5, 39-43. doi: 10.1016/0169-5347(90)90045-F

O'Connell, L. A., and Hofmann, H. A. (2011). Genes, hormones, and circuits: an integrative approach to study the evolution of social behavior. Front. Neuroendocrinol. 32, 320-335. doi: 10.1016/j.yfrne.2010.12.004

Ophir, A. G., Crino, O. L., Wilkerson, Q. C., Wolff, J. O., and Phelps, S. M. (2008). Female-directed aggression predicts paternal behavior, but female prairie voles prefer affiliative males to paternal males. Brain Behav. Evol. 71, 32-40. doi: 10.1159/000108609

Perrigo, G., Bryant, W. C., and vom Saal, F. S. (1990). A unique neural timing system prevents male mice from harming their own offspring. Anim. Behav. 39, 535-539. doi: 10.1016/S0003-3472(05)80419-1

Previti, D., and Amato, P. R. (2004). Is infidelity a cause or a consequence of poor marital quality? J. Soc. Pers. Relat. 21, 217-230. doi: 10.1177/0265407504041384

Pultorak, J. D., Fuxjager, M. J., Kalcounis-Rueppell, M. C., and Marler, C. A. (2015). Male fidelity expressed through rapid testosterone suppression of ultrasonic vocalizations to novel females in the monogamous California mouse. Horm. Behav. 70, 47-56. doi: 10.1016/j.yhbeh.2015. 02.003

Pultorak, J. D., Matusinec, K., Miller, Z. K., and Marler, C. A. (2017). Ultrasonic vocalization production and playback predicts intra-pair and extrapair social behavior in a monogamous mouse. Anim. Behav. 125, 13-23. doi: 10.1016/j.anbehav.2016.12.023

Remage-Healey, L., Adkins-Regan, E., and Romero, L. M. (2003). Behavioral and adrenocortical responses to mate separation and reunion in the zebra finch. Horm. Behav. 43, 108-114. doi: 10.1016/S0018-506X(02)00012-0

Ribble, D. O. (1991). The monogamous mating system of Peromyscus californicus as revealed by DNA fingerprinting. Behav. Ecol. Sociobiol. 29, 161-166. doi: $10.1007 / \mathrm{BF} 00166397$

Ribble, D. O. (1992). Lifetime reproductive success and its correlates in the monogamous rodent, Peromyscus californicus. J. Anim. Ecol. 61, 457-468. doi: $10.2307 / 5336$

Ribble, D. O., and Salvioni, M. (1990). Social organization and nest co-occupancy in Peromyscus californicus, a monogamous rodent. Behav. Ecol. Sociobiol. 26, 9-15. doi: 10.1007/BF00174020 
Rieger, N. S., and Marler, C. A. (2018). The function of ultrasonic vocalizations during territorial defence by pair-bonded male and female California mice. Anim. Behav. 135, 97-108. doi: 10.1016/j.anbehav.2017.1 1.008

Rosenfeld, C. S., Johnson, S. A., Ellersieck, M. R., and Roberts, R. M. (2013). Interactions between parents and parents and pups in the monogamous California mouse (Peromyscus californicus). PLoS ONE 8:e75725. doi: 10.1371/journal.pone.0075725

Schroeder, J., Hsu, Y., Winney, I., Simons, M., Nakagawa, S., and Burke, T. (2016). Predictably philandering females prompt poor paternal provisioning. Am. Nat. 188, 219-230. doi: 10.1086/687243

Shepherd, R. E., and French, J. A. (1999). Comparative analysis of sociality in lion tamarins (Leontopithecus rosalia) and marmosets (Callithrix kuhli): responses to separation from long-term pairmates. J. Comp. Psych. 113, 24-32. doi: 10.1037/0735-7036.113.1.24

Smith, J. N., Goldizen, A. W., Dunlop, R. A., and Noad, M. J. (2008). Songs of male humpback whales, Megaptera novaeangliae, are involved in intersexual interactions. Anim. Behav. 76, 467-477. doi: 10.1016/j.anbehav.2008.02.013

Snowdon, C. T., and Elowson, A. M. (1999). Pygmy marmosets modify call structure when paired. Ethology 105, 893-908. doi: 10.1046/j.1439-0310.1999.00483.x

Spoon, T. R., Millam, J. R., and Owings, D. H. (2007). Behavioural compatibility, extrapair copulation and mate switching in a socially monogamous parrot. Anim. Behav. 73, 815-824. doi: 10.1016/j.anbehav.2006. 10.010

Starkey, N. J., and Hendrie, C. A. (1998). Disruption of pairs produces pair-bond disruption in male but not female Mongolian gerbils. Physiol. Behav. 65, 497-503. doi: 10.1016/S0031-9384(98)00 190-5

Sun, P., Smith, A. S., Lei, K., Liu, Y., and Wang, Z. (2014). Breaking bonds in male prairie vole: long-term effects on emotional and social behavior, physiology, and neurochemistry. Behav. Brain Res. 265, 22-31. doi: 10.1016/j.bbr.2014.0 2.016
Sweeney, M. M., and Horwitz, A. V. (2001). Infidelity, initiation, and the emotional climate of divorce: are there implications for mental health? J. Health Soc. Behav. 42, 295-309. doi: 10.2307/3090216

Trivers, R. L. (1972). "Parental investment and sexual selection," in Sexual Selection and the Descent of Man, 1871-1971, ed B. Campbell (Chicago, IL: Aldine), $136-179$.

Uller, T., and Olsson, M. (2008). Multiple paternity in reptiles: patterns and processes. Mol. Ecol. 17, 2566-2580. doi: 10.1111/j.1365-294X.2008.03772.x

Wang, Z., and Aragona, B. J. (2004). Neurochemical regulation of pair bonding in male prairie voles. Physiol. Behav. 83, 319-328. doi: 10.1016/j.physbeh.2004.08.024

Westneat, D. F., Sherman, P. W., and Morton, M. L. (1990). "The ecology and evolution of extra-pair copulations in birds," in Current Ornithology, ed D. M. Power (New York, NY: Plenum Press), 331-369.

Wittenberger, J. F., and Tilson, R. L. (1980). The evolution of monogamy: hypotheses and evidence. Annu. Rev. Ecol. Syst. 11, 197-232. doi: 10.1146/annurev.es.11.110180.001213

Zimmermann, E. (2018). "High frequency/ultrasonic communication in basal primates: the mouse and dwarf lemus of Madagascar," in Handbook of Ultrasonic Vocalization, Vol. 25. ed S. M. Brudzynski (London, UK: Academic Press; HBBN), 521-531.

Conflict of Interest Statement: The authors declare that the research was conducted in the absence of any commercial or financial relationships that could be construed as a potential conflict of interest.

Copyright (c) 2018 Pultorak, Alger, Loria, Johnson and Marler. This is an open-access article distributed under the terms of the Creative Commons Attribution License (CC $B Y)$. The use, distribution or reproduction in other forums is permitted, provided the original author(s) and the copyright owner(s) are credited and that the original publication in this journal is cited, in accordance with accepted academic practice. No use, distribution or reproduction is permitted which does not comply with these terms. 